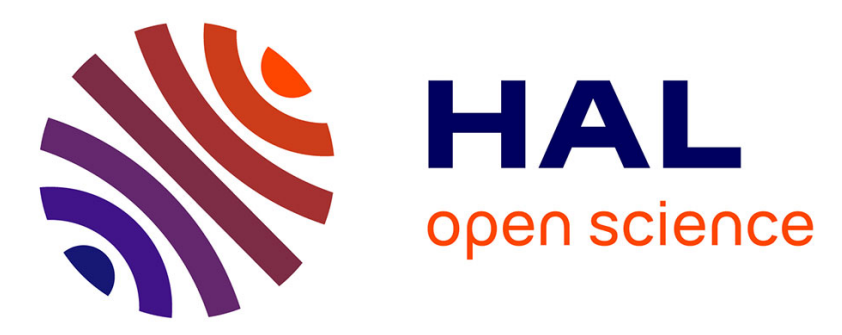

\title{
An integrated multiscale approach to heap leaching of uranium-ore agglomerates
}

Emerence Hoummady, Fabrice Golfier, Michel Cathelineau, Laurent Truche, Nicolas Durupt, Jean-Jacques Blanvillain, Jérémy Neto, Eric Lefevre

\section{- To cite this version:}

Emerence Hoummady, Fabrice Golfier, Michel Cathelineau, Laurent Truche, Nicolas Durupt, et al.. An integrated multiscale approach to heap leaching of uranium-ore agglomerates. Hydrometallurgy, 2018, 178, pp.274-282. 10.1016/j.hydromet.2018.05.011 . hal-02483617

\section{HAL Id: hal-02483617 \\ https://hal.univ-lorraine.fr/hal-02483617}

Submitted on 15 Oct 2020

HAL is a multi-disciplinary open access archive for the deposit and dissemination of scientific research documents, whether they are published or not. The documents may come from teaching and research institutions in France or abroad, or from public or private research centers.
L'archive ouverte pluridisciplinaire HAL, est destinée au dépôt et à la diffusion de documents scientifiques de niveau recherche, publiés ou non, émanant des établissements d'enseignement et de recherche français ou étrangers, des laboratoires publics ou privés. 


\title{
An integrated multiscale approach to heap leaching of uranium-ore agglomerates
}

\author{
Emerence Hoummady $^{\mathrm{a}, *}$, Fabrice Golfier ${ }^{\mathrm{a}}$, Michel Cathelineau ${ }^{\mathrm{a}}$, Laurent Truche ${ }^{\mathrm{a}, \mathrm{b}}$, \\ Nicolas Durupt $^{c}$, Jean-Jacques Blanvillain ${ }^{c}$, Jeremy Neto ${ }^{c}$, Eric Lefevre ${ }^{a}$ \\ ${ }^{a}$ Université de Lorraine, CNRS, CREGU, GeoRessources Lab., 54518 Vandoeuvre-lès-Nancy Cedex, France \\ ${ }^{\mathrm{b}}$ Université Grenoble Alpes, CNRS, ISTerre, F-38000 Grenoble, France \\ ${ }^{c}$ AREVA Mines, SEPA, 2 route de Lavaugrasse, 87250 Bessines-sur-Gartempe, France
}

\section{A R T I C L E I N F O}

\section{Keywords:}

Agglomerates

Heap leaching

Uranium ore

Scale-up

Column leaching tests

Clogging

Modelling

\begin{abstract}
A B S T R A C T
In heap leaching, agglomeration of clay rich ores is commonly used and may prevent plugging phenomena within heaps, but is not always successful. In order to better understand the heap leaching process of uranium ore agglomerates, a multi-scale approach, based on 10-cm and meter-scale columns, was used to achieve a Representative Elementary Volume (REV) of packed agglomerates. Flow rate and agglomerate size distribution were found to have no impact on the ore leaching kinetics. An increase of the sulfuric acid content of the leaching solution caused a slight increase of uranium extraction. Meter-scale tests indicated that scaling up had no significant influence on extraction kinetics. Some tests have also shown that column porosity and permeability decreased during irrigation and with the heap depth. This led to the occurrence of plugging. X-ray tomography analyses on clogged sections of the column revealed that this phenomenon arises from agglomerate mechanical degradation. In addition, an integrative numerical model of the leaching of the meter scale column of agglomerates was built, combining flow and reactive transport equations where the effective reaction term was directly inferred from the REV experiments. An excellent agreement was observed with the column tests.
\end{abstract}

\section{Introduction}

Heap leaching is an industrial method to process low grade ores, consisting of percolating an acid or alkaline leaching solution through a 4 to 10 meter high heap of crushed ore (Ghorbani et al., 2016). This technique is used to process several ores such as uranium, copper or nickel laterites and is based on fluid-rocks interactions at the heap scale and on the percolation of the leaching solution through ore porosity to dissolve minerals of interest at the micro-scale (Bartlett, 1997). In this way, the accessibility of these minerals by the leaching solution is a limiting factor (Ghorbani et al., 2011).

Due to the significant size of heaps and the long leaching time (about 1 year for a 6 to $9 \mathrm{~m}$ high heap), heap leaching processes may be difficult to investigate. Smaller size experimental models and numerical models are used instead. Experimentally, columns from 0.5 to $6 \mathrm{~m}$ high are used to reproduce leaching conditions (Bennett et al., 2012; Robertson, 2017). Such tests allow analysing the influence of the different leaching parameters. However, they may contain a bias: Bouffard and West-Sells (2009) noted that the leached ore density decreased with the decrease of column diameter. This scale reduction decreases the ore packing density, due to wall effects, which subtly alters mechanical behaviour in the case of column leaching. In addition, heterogeneities present in the heap, such as a wide particle size distribution or the presence of inert materials, may cause an overestimation of the leaching rate measured in columns compared to that measured in situ. Numerical models (Dixon and Hendrix, 1993; Mellado et al., 2009) using parameters fitted to experimental data were also developed, in order to study the impact of the different leaching parameters (Ghorbani et al., 2016) from very simplified analytical models to more complex mechanistic approaches. They classically describe fluid flow and transport of leached solution through the heap and reaction kinetics with the minerals of interest (Dixon, 2003; Dixon and Petersen, 2003). Depending on the operating conditions (evolution of heap packing or of the heat within the heap), additional couplings may be required (Dixon, 2000; Valencia et al., 2008). Note that several models were proposed in the literature but few are used in industrial applications (Ghorbani et al., 2016; Robertson, 2017). The main difference between these models lies in the governing assumptions and the related mass balance equations used to represent dissolved species transport, leaching solution flow and the reactional model. The Richards equation

\footnotetext{
* Corresponding author.

E-mail address: emerence.hoummady@univ-lorraine.fr (E. Hoummady).
} 


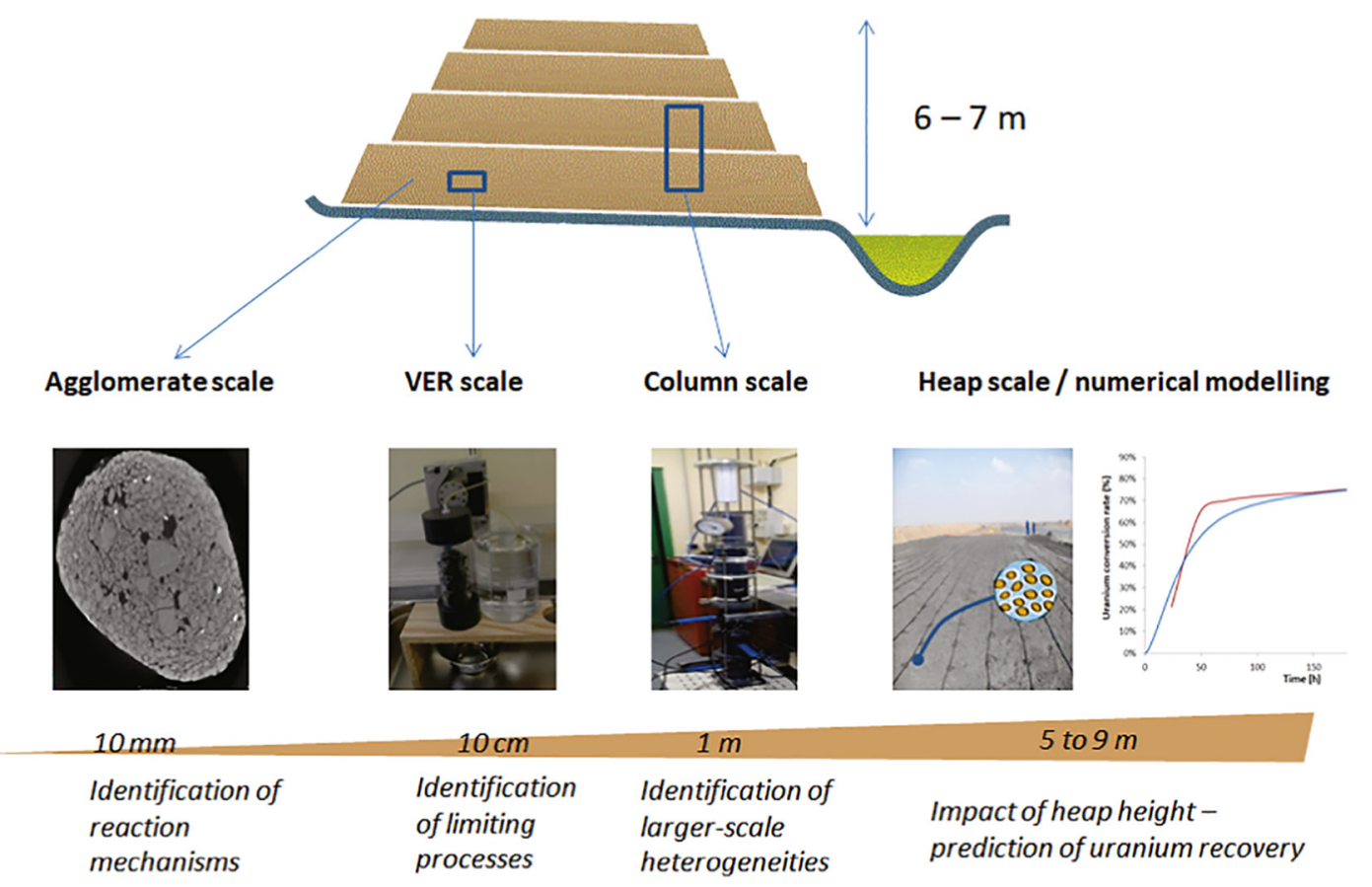

Fig. 1. Multi-scale analysis of uranium ore agglomerates leaching.

in combination with the traditional Mualem-Van Genuchten model is usually chosen to model solution flow through the heap (Robertson, 2017) as leaching are often occurs under partially saturated conditions. However a generalised Darcy model may also be used when the gas phase is considered (Bennett et al., 2012). Moreover, two types of leaching transport models may be distinguished depending on the level of column heterogeneity (Golfier et al., 2007): (i) models considering the heap as a homogeneous medium controlled by diffusion or advection (Bennett et al., 2012) and (ii) dual porosity models, considering the heap as two distinct regions: a stagnant region and a mobile one (Bouffard and Dixon, 2001; Dixon and Petersen, 2003; Robertson, 2017). Such models can closely emulate heap behaviour in case of channelling (Ogbonna et al., 2006). At the mineral particle scale, the easiest approach is to consider a uniform reaction model ("uniform- or homogeneous-reaction model"), meaning a uniform penetration of leaching solution within particles, independently of their size. However, when diffusion is limiting (Sheikhzadeh and Mehrabian, 2007), most models use the shrinking core model to describe reactions between minerals and leaching solution (Bennett et al., 2012; Robertson, 2017). Although the shrinking core model is easy to apply, it supposes that the particles to be leached are spherical and that minerals distribution is homogeneous, which is not the case in experimental tests (Bennett et al., 2012). All of these models led to identify and assess parameters that influence heap leaching efficiency such as heap temperature or leaching reagent concentration which both impact the dissolution kinetics (Bartlett, 1997; Petersen, 2016). Ghorbani et al. (2011) also point out heap permeability as a key factor of heap leaching. If percolation of leaching solution is too slow, chemical reactions between reagent and minerals cannot occur and on the other hand, if this characteristic time is too long, it might result in the flooding of the ore (Ghorbani et al., 2016). In addition, a low porosity may enhance plugging, causing a decrease of leaching efficiency and heap collapsing. An uneven permeability is also reported to induce channelling and to prevent irrigation of some parts of the heap. Such permeability difficulties are mostly caused by the nature of the ore and especially high clay and fine particles content.

To solve this problem, the nickel, copper and uranium industries use agglomeration, consisting of increasing ore particle size distribution by binding fines and clays together into larger particles. This improves heap permeability and stability and also prevents fines migration during leaching (Bartlett, 1997; Bouffard, 2005; Yijun et al., 2004). Note that most studies of agglomerate heap leaching focus on copper or nickel laterite ore (Dhawan et al., 2013; Kodali et al., 2011; Nosrati et al., 2012a,b) but up to now, the behaviour of uranium-ore agglomerates remains poorly understood. The only exception is the recent study of Hoummady et al. (2017) who have identified changes in the structure of uranium-ore agglomerates during leaching.

Here, we focus on leaching effects at the agglomerate scale and at the Representative Elementary Volume (REV) scale (by the use of small column leaching tests). The objective of the current work is to upscale these results to the heap scale, by using both REV leaching experiments, meter scale columns leaching tests and numerical modelling. An integrative multiscale approach, illustrated in Fig. 1, is conducted for this purpose by (i) identifying the limiting processes at the smaller scale, (ii) stating the governing assumptions at the heap scale in terms of these latter processes and (iii) predicting the uranium extraction. In addition, this study also intends to characterize and understand plugging.

\section{Materials and methods}

\subsection{Ore, agglomeration and leaching processes}

The agglomerates used in this study were produced from clay-rich sandstone containing about $900 \mathrm{ppm}$ of uranium and $>10 \mathrm{wt} \%$ of clay minerals (mainly kaolinites, illites, mixed layered illite-smectite phases and chlorites) provided by AREVA and originating from Somaïr, Niger. Most of the uranium in this ore is hosted by clay minerals and especially by chlorites. In addition, this ore contains a low amount of carbonate ( $0.4 \mathrm{wt} \%)$ and calcium $(0.29 \mathrm{wt} \%)$, compared to the aluminium content $(8.32 \mathrm{wt} \%)$. Due to this feature and to the high clay content, this ore is ideally suited for a study of the agglomeration process.

Crushed ore was agglomerated with water and sulfuric acid, at a ratio of $25 \mathrm{~kg}$ of acid per $1000 \mathrm{~kg}$ of ore for a liquid/solid ratio of $0.08 \mathrm{~kg} / \mathrm{kg}$, within a cement mixer at a speed of $32 \mathrm{rpm}$. Half of the water was first mixed with the dry ore. Sulfuric acid mixed with the rest of the water was then added to the ore and the agglomeration carried on for $3 \mathrm{~min}$. Then, agglomerates were stored for curing during at least $24 \mathrm{~h}$ to harden the bonds between particles (Pietsch, 2002). 
Table 1

Leaching parameters used in the experimental tests.

\begin{tabular}{llll}
\hline Batch & Agglomerates diameter & Flowrate & Sulfuric acid ratio \\
\hline$\# 1(\mathrm{RC})$ & $10 \mathrm{~mm}$ & $7.2 \mathrm{ml} / \mathrm{h}\left(\right.$ i.e. $\left.61 / \mathrm{m}^{2} / \mathrm{h}\right)$ & $10 \mathrm{~g} / \mathrm{l}$ \\
$\# 2$ & $10 \mathrm{~mm}$ & $7.2 \mathrm{ml} / \mathrm{h}$ & $5 \mathrm{~g} / \mathrm{l}$ \\
$\# 3$ & $10 \mathrm{~mm}$ & $7.2 \mathrm{ml} / \mathrm{h}$ & $20 \mathrm{~g} / \mathrm{l}$ \\
$\# 4$ & $5 \mathrm{~mm}$ & $7.2 \mathrm{ml} / \mathrm{h}$ & $10 \mathrm{~g} / \mathrm{l}$ \\
$\# 5$ & $20 \mathrm{~mm}$ & $7.2 \mathrm{ml} / \mathrm{h}$ & $10 \mathrm{~g} / \mathrm{l}$ \\
$\# 6$ & $10 \mathrm{~mm}$ & $3.6 \mathrm{ml} / \mathrm{h}$ & $10 \mathrm{~g} / \mathrm{l}$ \\
\hline
\end{tabular}

\subsection{REV-scale leaching tests}

A series of leaching tests in small columns were conducted to assess the existence of mass transfer limitations within and around the agglomerates. At the REV scale, such limitations can be due to (i) the diffusion through the fluid boundary layer surrounding the agglomerates (external transfer limitation) and (ii) the diffusion through the pores within the agglomerate (internal mass transfer limitation). In addition, the impact of acid concentration, which can be a rate-limiting step for the reaction, was also evaluated. Experimental results discussed hereafter will be used as a basis for our upscaling analysis. Note that characterizing the structure of uranium-ore agglomerates prior to and after leaching was previously discussed in Hoummady et al. (2017) and the impact of agglomeration conditions on heap leaching efficiency was investigated in Hoummady et al. (2017). Interested readers can refer to Hoummady et al. (2017) for more details about the experimental setup and analytical methods.

About 120 to $150 \mathrm{~g}$ of agglomerates of uniform diameter were packed in a column of $10 \mathrm{~cm}$ high and $4 \mathrm{~cm}$ diameter and leached over 10 days with a diluted sulfuric acid solution at a given flowrate defined in Table 1. This volume of agglomerates, corresponding to a homogeneous porous medium, is expected to be large enough to achieve a REV of the entire heap. The first batch from Table 1 corresponds to the reference leaching conditions and is noted as RC-batch. The leach solution was sampled daily and analysed by ICP-OES after dilution by a factor 10 with 2 vol\% nitric acid (results are given with a measurement uncertainty of $10 \%$ ). The extraction of each element was calculated as moles contained in the leach solution to the total moles within the ore, at the initial time. The dimensionless extraction rate $\eta$ was also calculated for each element as the ratio between the current extent and the final extent of extraction.

\subsection{Meter-scale column leaching tests}

To scale-up leaching studies, they were carried out in a $1 \mathrm{~m}$ tall and $10 \mathrm{~cm}$ diameter column randomly packed with 9 to $10 \mathrm{~kg}$ of variablesize agglomerates. Agglomerates were leached for 13 days with a $10 \mathrm{~g} / 1$ sulfuric acid solution and at a flowrate of $45 \mathrm{ml} / \mathrm{h}$ (corresponding to a specific flowrate of $61 / \mathrm{m}^{2} / \mathrm{h}$ ). These conditions are similar to the reference conditions (RC) defined in Table 1 for 10-cm high columns, using the same surface flow rate and the same sulfuric acid concentration. In addition, to simulate leaching conditions at different depths within the heap, a constant compressive axial load was exerted on the $1 \mathrm{~m}$ tall column corresponding to the vertical stress of the equivalent mass of the overlying material. Three representative depths of the heap leaching process $(0-1 \mathrm{~m}, 3-4 \mathrm{~m}$ and 5-6 m) were considered. As for the small columns tests, the leached solution was sampled daily and analysed by ICP-OES (results are given with an uncertainty of 10\%). The column weight and the saturation index of the column at different heights $(0.3 \mathrm{~m}, 0.5 \mathrm{~m}, 0.7 \mathrm{~m}$ and $0.9 \mathrm{~m})$ were measured every $5 \mathrm{~min}$ by means of the Balance Link software and Trime Pico64 TDR probes. Due to column settlement, causing a modification of the porosity, these probes had to be recalibrated during the tests. These data were used to calculate the column total porosity throughout leaching. Air permeability measurements before and after leaching were also done. Experiments were repeated twice to assess reproducibility of the results.

After each experiment, the columns were partially disassembled into 5 subsections of $20 \mathrm{~cm}$ tall for post-mortem dry mass and water content measurement. In case of plugging, plugged areas were sampled and analysed by X-ray tomography with a Nanotom Phoenix tomograph with a resolution of $50 \mu \mathrm{m}$. Results were then processed, using $V G$ Studio Max 2.2 software to determine the macro-porosity of the clogged sections.

\section{Results and discussion}

\subsection{Influence of leaching parameters}

Three main leaching parameters were studied: (i) the sulfuric acid content of the leaching solution, (ii) the agglomerate size and (iii) the flowrate.

Two different leaching solutions were first tested. Increasing this concentration from $5 \mathrm{~g} / \mathrm{l}$ to $20 \mathrm{~g} / \mathrm{l}$ was found to slightly increase the uranium extraction (Fig. 2a). Such results are consistent with those of Hoummady et al. (2017). Sulfuric acid causes the dissolution of illites and kaolinites. Sulfuric acid concentration above $5 \mathrm{~g} / \mathrm{l}$ is enough and thus not the limiting reactant. Obviously, the small difference in uranium extraction might be economically important but the change measured is not statistically significant.

The influence of internal mass transfer on the uranium extraction rate was investigated by changing the agglomerate size (from 5 , to 10 and to $20-\mathrm{mm}$ diameter). The initial uranium content was found to decrease slightly and quasi-linearly with agglomerate diameter, causing an apparent decrease of the uranium extraction with increasing agglomerate size. Results in Fig. 2b were shown as a function of the $\eta$ ratio, calculated as the ratio between current extraction and the final extraction. This dimensionless extraction rate was used to consistently account for the initial varying uranium content and also agglomerates porosity variations (Fig. 2b). It was found to be the same except for the smallest agglomerates, which means that the uranium leaching kinetics was not significantly limited by internal mass transfer.

Batches \#1 and \#6 were carried out at two different flow rates, respectively 7.2 and $3.6 \mathrm{ml} / \mathrm{h}$, at constant acid concentration. For comparative purpose, the results in Fig. 1c-e are presented in terms of the $\mathrm{L} / \mathrm{S}$ ratio calculated as the mass of leached solution injected into the column divided by the initial mass of agglomerates within the column. Considering the measurement uncertainty, no major difference between the extraction for $\mathrm{Si}, \mathrm{Al}, \mathrm{Ca}$ or $\mathrm{K}$ was found at the two flowrates. As an example, Al extraction for both flow rates is shown in Fig. 2c (data not shown for the other species). Yet, this did not seem to be the case for uranium (Fig. 2d). Since a change in the initial uranium content between two batches of agglomerates was suspected, the dimensionless uranium extraction extent $\eta$ was also calculated, showing similar kinetics between the two flowrates tested (Fig. 2e). Due to the measurement error of $10 \%$ of the ICP OES, the differences of dimensionless uranium extraction rate between the flowrates were assumed not to be significant. There is no evidence of significant external mass transfer limitations for acid leaching in a $10 \mathrm{~cm}$ tall column (i.e. at the REV scale).

\subsection{Meter-scale column leaching}

\subsubsection{Evolution of the column behaviour during leaching and at different depths}

Leaching conditions and packed bed properties are reported in Table 2 for the three $1 \mathrm{~m}$-tall columns. A mass balance calculation has shown consistency between measurements of solution saturations and agglomerate column weight (Fig. 3a). Fig. 3b compares the change in the total mass of solution within the column as a function of the $\mathrm{L} / \mathrm{S}$ ratio for the two limiting cases of depth increment (0-1 and 5-6 m). 

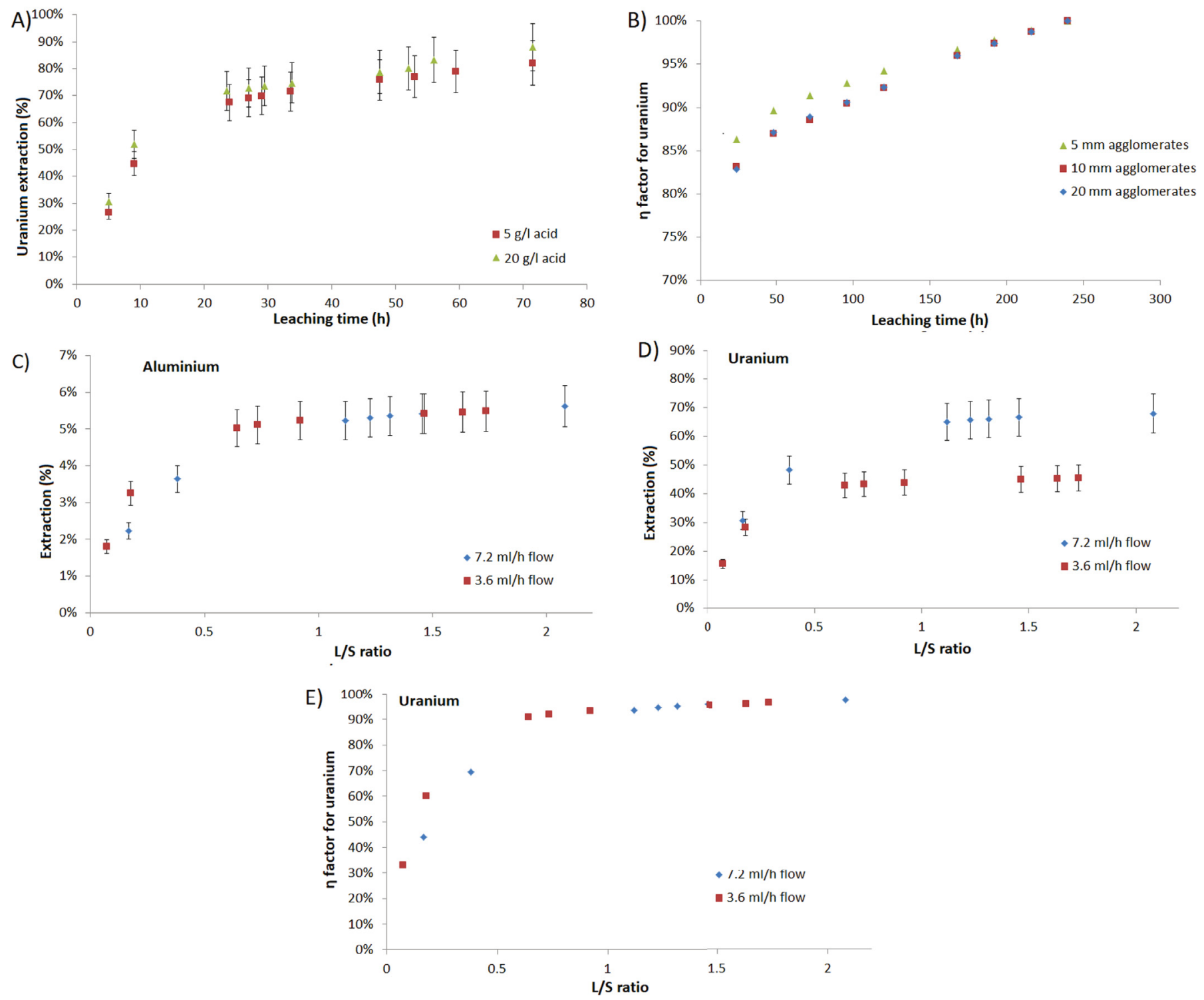

Fig. 2. Influence of acid concentration (A), agglomerate diameter (B) and leaching flowrate on aluminium (C), uranium extraction (D) and uranium $\eta$ factor (E).

Table 2

Characteristics of leaching tests.

\begin{tabular}{llll}
\hline Heap depth (m) & $0-1 \mathrm{~m}$ & $5-6 \mathrm{~m}$ & $5-6 \mathrm{~m}$ \\
\hline Leaching time (days) & 13 & 13 & 2 \\
Column density at $\mathrm{L} / \mathrm{S}=0.1$ & $1472.8 \mathrm{~kg} / \mathrm{m}^{3}$ & $1649.5 \mathrm{~kg} / \mathrm{m}^{3}$ & $1618.7 \mathrm{~kg} / \mathrm{m}^{3}$ \\
Column density at $\mathrm{L} / \mathrm{S}=0.9$ & $1456.9 \mathrm{~kg} / \mathrm{m}^{3}$ & $1686.8 \mathrm{~kg} / \mathrm{m}^{3}$ & - \\
Saturation rate at $\mathrm{L} / \mathrm{S}=0.9$ & $35.75 \%$ & $49.15 \%$ & - \\
Total porosity at L/S $=0.9$ & $52.06 \%$ & $44.62 \%$ & - \\
Settlement at L/S $=0.9 \%)$ & $15 \%$ & $15.4 \%$ & $12 \%$ \\
Clogging & No & No & Yes
\end{tabular}

Notes: $\mathrm{L} / \mathrm{S}=0.1$ corresponds to about 1 day after the beginning of leaching (transient state) and $\mathrm{L} / \mathrm{S}=0.9$ corresponds to about 7 days after the beginning of leaching (steady state).

Three steps can be highlighted: (i) a preliminary step of filling the column with solution corresponding to the time needed by the solution to percolate down to the bottom of the column (L/S ratio $<0.1$ for the $0-1 \mathrm{~m}$ depth), then (ii) a transient drainage step of the column $(0.1<\mathrm{L} / \mathrm{S}$ ratio $<0.25$ for the $0-1 \mathrm{~m}$ depth) and finally (iii) a steady state in which the mass fluxes of solution going in and out of the column are equal (L/S ratio $>0.25$ for the $0-1 \mathrm{~m}$ depth). The second step can be related to the settling of the material due to the variation in porefluid pressure when drainage occurs. This is consistent with the decrease of the total porosity observed during the early hours of irrigation (Fig. 3c). The total porosity decreases logically with depth. Permeability analyses reveal a similar trend (16 Darcy for the 0-1 m column and 7 Darcy for the 5-6 m column after settling). The establishment of steady state takes a longer time (Fig. 3b). In addition, water saturation on a vertical profile (i.e. during steady state) was measured at a ratio L/ $\mathrm{S}$ of 0.9 . Fig. $3 \mathrm{~d}$ highlights that the water saturation remains the same across the column. At the basis of the column, this rate slightly decreases probably due to the outflow geometry.

The $\mathrm{pH}$ of the feed and filtrate was similar, indicating that sulfuric acid was in excess for this scale. In this way, this factor is not a limiting factor for leaching. As extraction curves during leaching were similar to those obtained at REV scale (Hoummady et al., 2017), specific attention was paid to uranium and calcium. Fig. 4a shows that the calcium concentration exhibits a three-step trend. During the fill, the calcium concentration exceeded the gypsum solubility, which might cause precipitation. As gypsum was found to cause plugging (AgatziniLeonardou and Zafiratos, 2004), we estimated the total volume of gypsum which may be formed if all the calcium contained within the column precipitated. This volume reaches about $0.6 \%$ of the volume of 

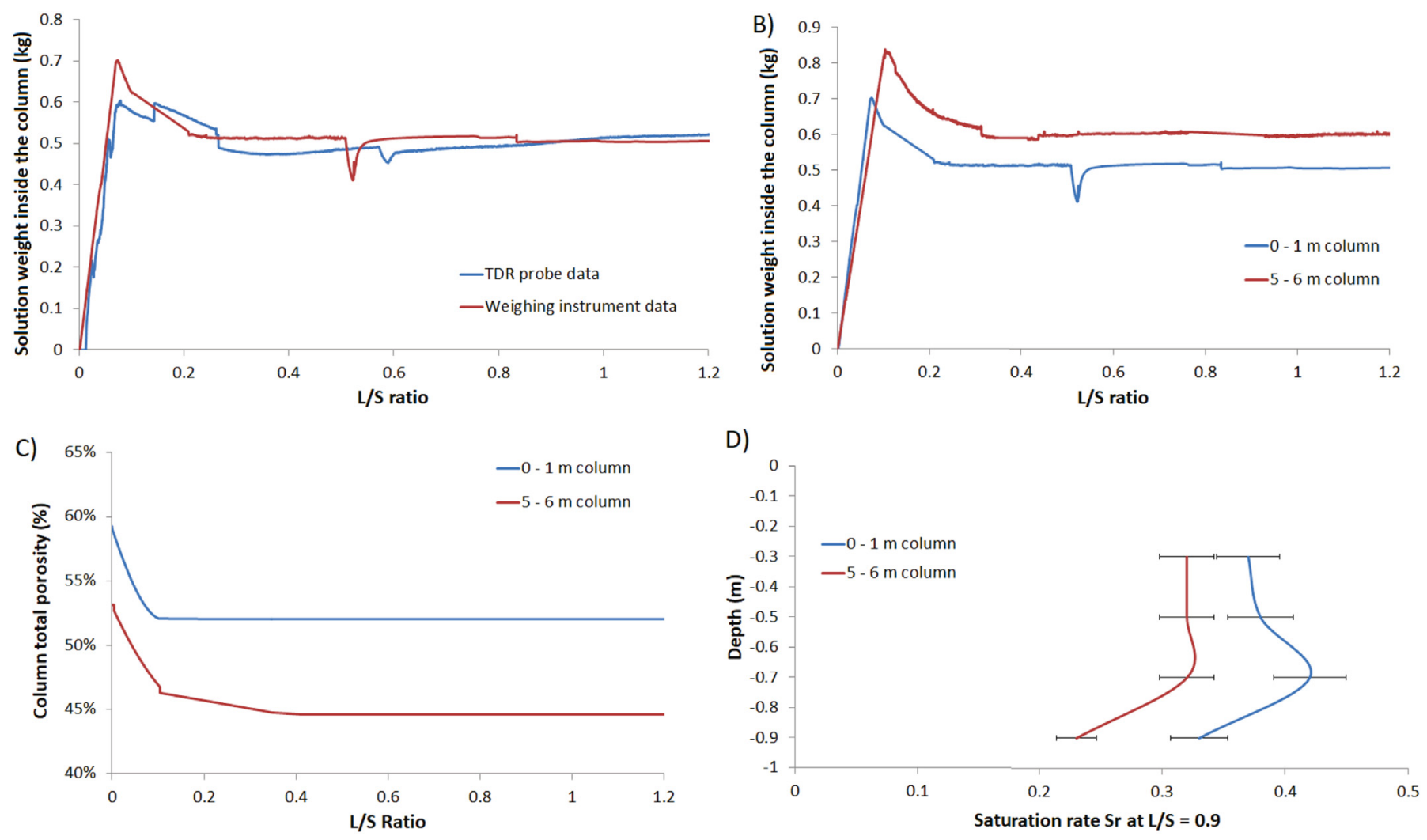

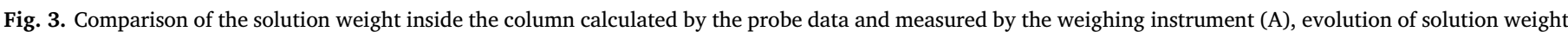
of the columns through time (B), changes in column porosity with time (C), and vertical saturation profile at L/S $=0.9$ (D). Notes: three steps are distinguished: a filling step, a drainage step and a steady step.
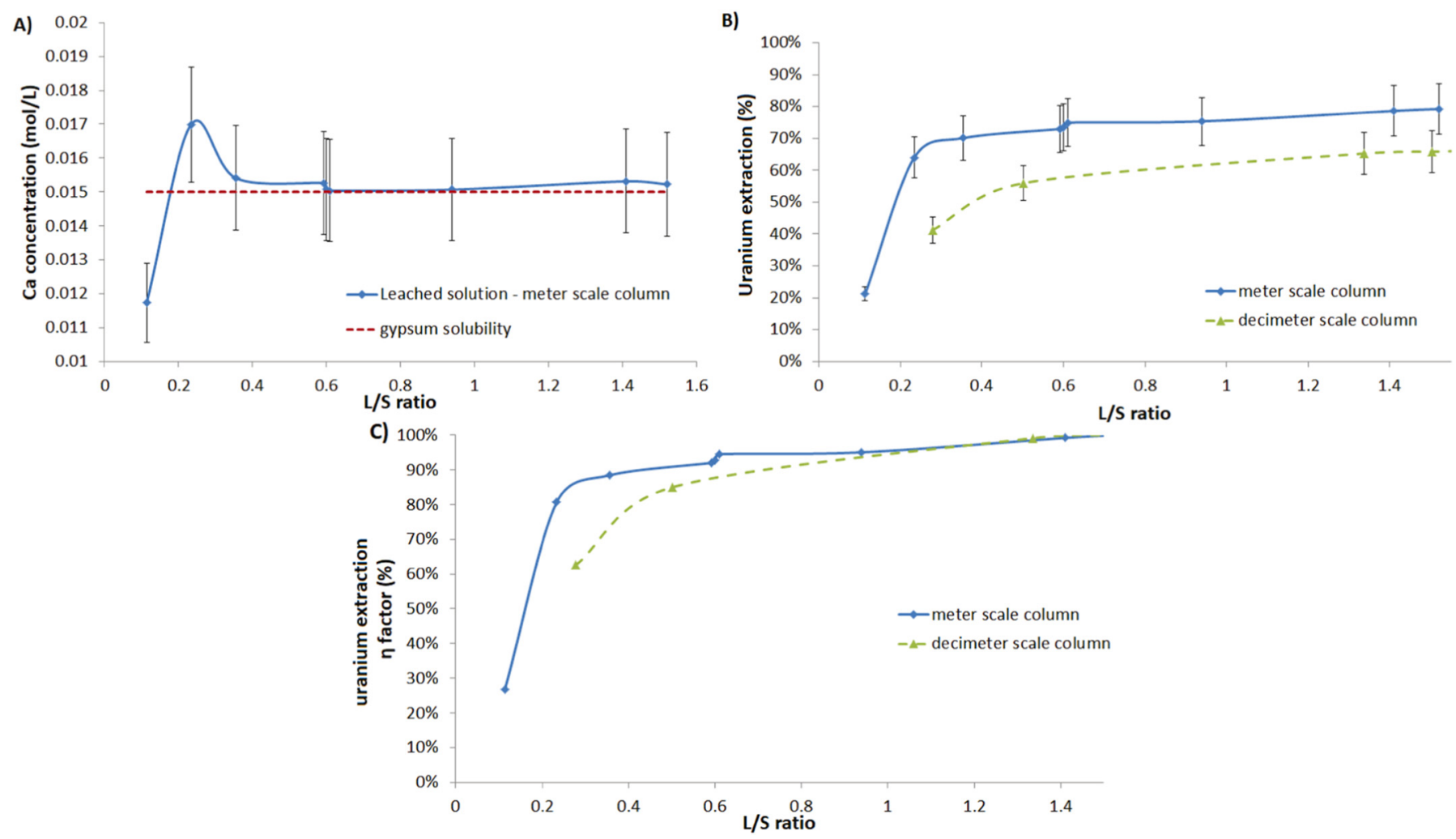

Fig. 4. Evolution of A) calcium concentration, B) uranium extraction and C) uranium $\eta$ factor during leaching.

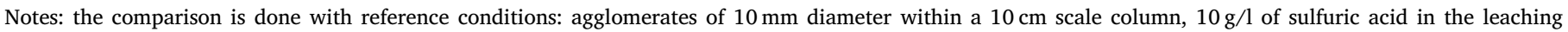
solution, and a flow rate of $7.2 \mathrm{ml} / \mathrm{h}$. 
the column, i.e. about $1 \%$ of the total porosity of the column. This value is too small to be the cause of plugging. Moreover, column homogeneity along its depth precludes the presence of localised precipitates due to heterogeneous calcium concentration. This finding will be confirmed by $\mathrm{X}$-ray images of plugged sections in the next section.

The final uranium extraction of $75 \%$ was higher than in the $10 \mathrm{~cm}$ tests but this depends on the agglomerate size of interest (extraction vary between $65 \%$ and $90 \%$ for $5 \mathrm{~mm}$ - to $20 \mathrm{~mm}$-diameter agglomerates in 10-cm columns). The uranium extraction rate $\eta$ was very similar for both tests (Fig. 4c). In other words, effective reaction (column-scale) and apparent reaction (REV scale) kinetics were very similar, thus validating the use of smaller column tests to study agglomerate leaching.

\subsubsection{Analysis of plugged areas}

To go further in the analysis, let us take a closer look at the way clogging occurs. Early on the tests, the two columns representing the conditions in the middle of the heap (3-4 m of depth) and one of the columns corresponding to the bottom (5-6 $\mathrm{m}$ of depth) plugged. In all cases, plugging occurred in the upper $20 \mathrm{~cm}$ layer, i.e. where the maximal vertical stress due to initial pre-compaction applies. The plugged sections were analysed by X-ray tomography and compared to a non-plugged unleached section (Fig. 5a,b). In the latter section, agglomerates were noticeable contrary to the plugged section where no structure was observed. Agglomerates are mechanically degraded by the weight of the heap above, subsequently causing clogging. We presume that the weight of the material above and the settling during the first step of leaching deformed the agglomerates and, combined with acid solution percolation, gradually caused their degradation. This also decreased the porosity between agglomerates from $44 \%$ to $7 \%$ and permeability from 17 to 6 Darcy (Table 3). Saturation increased and also enhanced agglomerate degradation. Pore connectivity was also found to decrease when plugged, as shown in Fig. 5d, leading to
Table 3

Evolution of sections macro porosity and permeability caused by clogging.

\begin{tabular}{lll}
\hline & Macro porosity (\%) & Permeability (Da) \\
\hline Unclogged section & $44 \%$ & $17 \mathrm{Da}$ \\
Clogged section & $7 \%$ & $6 \mathrm{Da}$ \\
\hline
\end{tabular}

solution channelling, unlike in the non-plugged section where porosity was uniform (Fig. 5c) and solution flowed homogeneously.

\subsection{Numerical model of acid leaching of uranium-ore agglomerates at the 1-m column-scale}

\subsubsection{Governing assumptions of the model}

At this point, we have to infer from REV experiments the governing assumptions for heap acid leaching and build a numerical model capable of predicting the uranium extraction rate. Effective reaction kinetics will be directly upscaled from REV measurements so that lowerscale information is not discarded. Model assumptions that govern flow and transport processes can be stated as follows:

(i) The acid flow is assumed to be one-dimensional (from the top to the bottom of the heap) under variably saturated conditions.

(ii) Mass transfer limitations (both internal and external) do not significantly affect the observed reaction rate as shown by REV-scale tests and are also neglected at the column scale.

(iii) Uranium dissolution kinetics is not influenced by the extraction rate of the other elements in solution. Uranium dissolution and mass transport down the column can therefore be uncoupled and modelled independently of other mineral species.

(iv) Acid is assumed to be in large excess so that it is constant with time
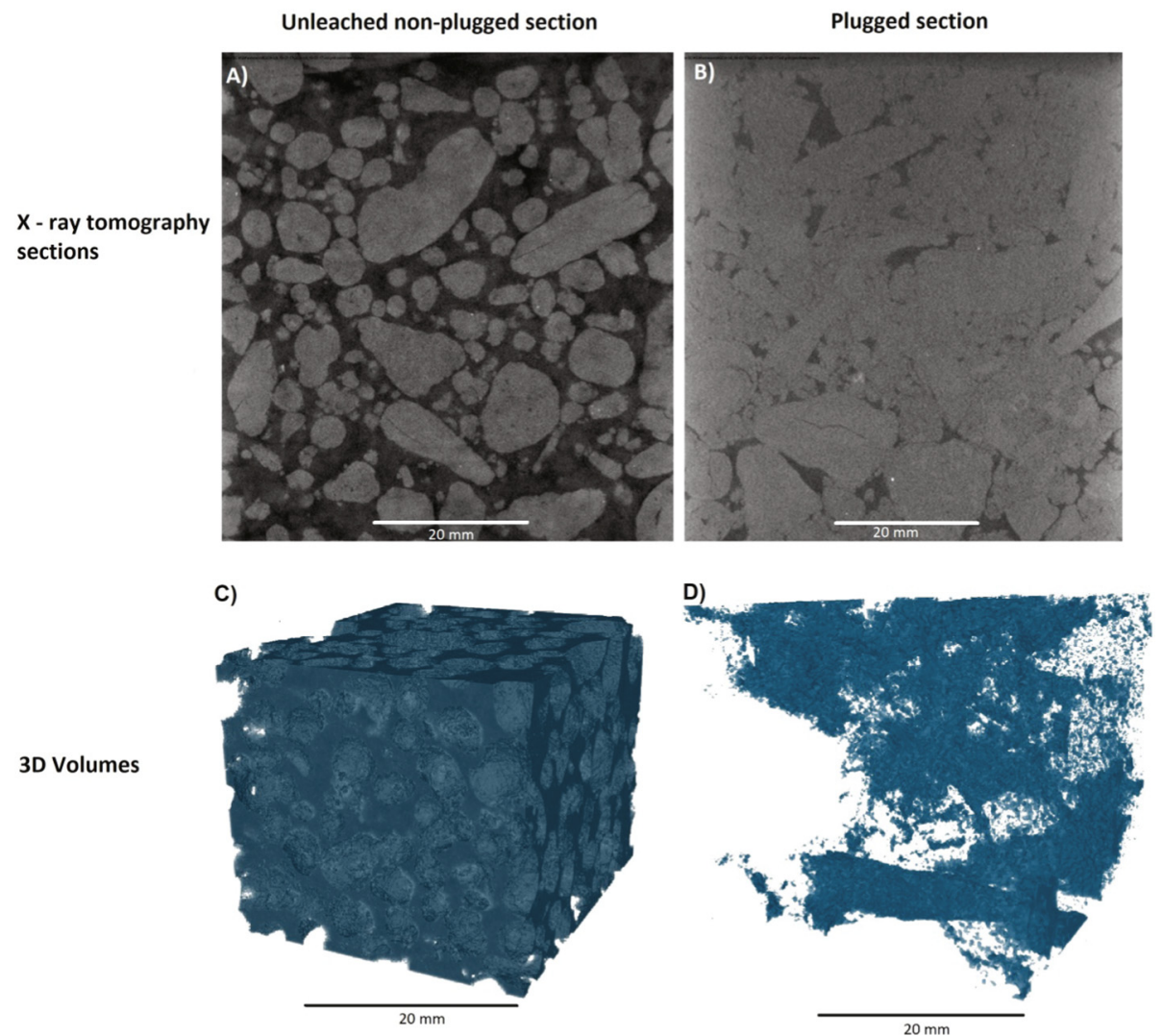

Fig. 5. X-ray tomography analyses of A) unleached non-plugged section B) leached plugged section and 3D porosity volume of C) unleached non plugged section and D) leached plugged section. 
and all along the column. No mass balance equation is required for acid species.

(v) In a first step, hydro-mechanical coupling is discarded so that changes in porosity and permeability are neglected. As a consequence, we will focus only on $0-1 \mathrm{~m}$ column leaching tests and the transient behaviour before bed settlement will not be explicitly simulated.

The resulting model has been built with the COMSOL Multiphysics 4.2 software, using parameters deduced from our experiments. A 1D meter-scale column, having dimensions similar to those we used, was modelled.

\subsubsection{Flow model}

Fluid flow in the variably-saturated column was modelled using the Richards equation coupled with the model of Van Genuchten and Mualem:

$\left(C+S_{e} S\right) \frac{\partial h_{c}}{\partial t}+\frac{\partial}{\partial z}\left(-K_{w}^{*}(\theta) \frac{\partial}{\partial z} h_{c}\right)=0$

where the apparent hydraulic conductivity $K_{w}{ }^{*}(\theta)$ is defined by:

$K_{w}^{*}(\theta)=K_{w} k_{r w}=\frac{\rho_{w} g k}{\mu_{w}} k_{r w}(\theta)$

with $S$, the specific storage coefficient $\left(\mathrm{m}^{-1}\right), S_{e}$, the effective saturation $(-), C$, is the specific moisture capacity $\left(\mathrm{m}^{-1}\right), z$, the vertical elevation (m), $\theta$, the water volume fraction $(-), t$, is time (s), $k$, the intrinsic permeability $\left(\mathrm{m}^{2}\right), \mu_{\mathrm{w}}$ the dynamic viscosity of water $(\mathrm{Pa} / \mathrm{s}), K_{w}$, the water hydraulic conductivity $(\mathrm{m} / \mathrm{s}), k_{r w}$, the water relative permeability $(-)$, and $h_{c}=p_{w} / \rho_{w,} g$ the hydraulic head (m) where $p_{w}$ is the water pore pressure $(\mathrm{Pa})$ and $\rho_{w}$, the water density $\left(\mathrm{kg} / \mathrm{m}^{3}\right)$.

Changes in relative conductivity, soil moisture and pressure head are described by the following relationships: (Mualem, 1976; Van Genuchten, 1980)

$\theta=\left\{\begin{aligned} \theta_{r}+\left(\theta_{s}-\theta_{r}\right) S_{e}, & h_{c}<0 \\ \theta_{s}, & h_{c} \geq 0\end{aligned}\right.$

$S_{e}=\left\{\begin{aligned} \frac{1}{\left(1+\left|\alpha h_{c}\right|^{n}\right)^{m}}, & h_{c}<0 \\ 1, & h_{c} \geq 0\end{aligned}\right.$

$C=\left\{\begin{aligned} \frac{\alpha m}{1-m}\left(\theta_{s}-\theta_{r}\right) S_{e}^{\frac{1}{m}}\left(1-S_{e}^{\frac{1}{m}}\right)^{m}, & h_{c}<0 \\ 0, & h_{c} \geq 0\end{aligned}\right.$

$k_{r w}=\left\{\begin{aligned} S_{e}^{l}\left(1-\left(1-S_{e}^{\frac{1}{m}}\right)^{m}\right)^{2}, & h_{c}<0 \\ 1, & h_{c} \geq 0\end{aligned}\right.$

We denote $\theta_{s}$ and $\theta_{r}$ the residual and saturated water content respectively. $\alpha, m, l$ and $n$ are the Mualem-Van Genuchten parameters.

Initially, the column has a uniform pressure head fixed at $-0.075 \mathrm{~m}$. An inward flux is imposed at the inlet as $N_{0}=1.41 \cdot 10^{-3} \mathrm{~kg} / \mathrm{m}^{2} \mathrm{~s} \mathrm{~N}_{0}=1.41 \cdot 10^{-3} \mathrm{~kg} / \mathrm{m}^{2} \mathrm{~s}$ (corresponding to a volume flow rate per unit area of $6 \mathrm{l} / \mathrm{m}^{2} / \mathrm{h}$ ) and a free drainage boundary condition is imposed at the outlet. Numerical parameters fitted against experimental saturation curves are shown in Table 4. Both hydraulic conductivity and water volume fractions were extracted from data coming from meter scale column experiments (Tables 2 and 3).

The average saturation curves and local profiles at different crosssections are presented in Fig. 6. The comparison reveals a very good agreement between experimental data and numerical predictions for the mean effective saturation during steady state. The TDR measurements give similar conclusions. Although the model is constrained by experimental data, this nice concordance supports the initial hypotheses on the fluid flow behaviour within the column (no channelling
Table 4

Parameters used for the flow model.

\begin{tabular}{ll}
\hline Parameter & Value \\
\hline Hydraulic conductivity $\mathrm{K}_{\mathrm{w}}(\mathrm{m} / \mathrm{s})$ & $1.610^{-4} \mathrm{~m} / \mathrm{s}$ \\
Water volume fraction at saturation $\theta_{\mathrm{s}}$ & 0.58 \\
Residual water volume fraction $\theta_{\mathrm{r}}$ & 0.09 \\
$\alpha$ & 19.297 \\
$n$ & 8 \\
$l$ & 0.689 \\
\hline
\end{tabular}

A)
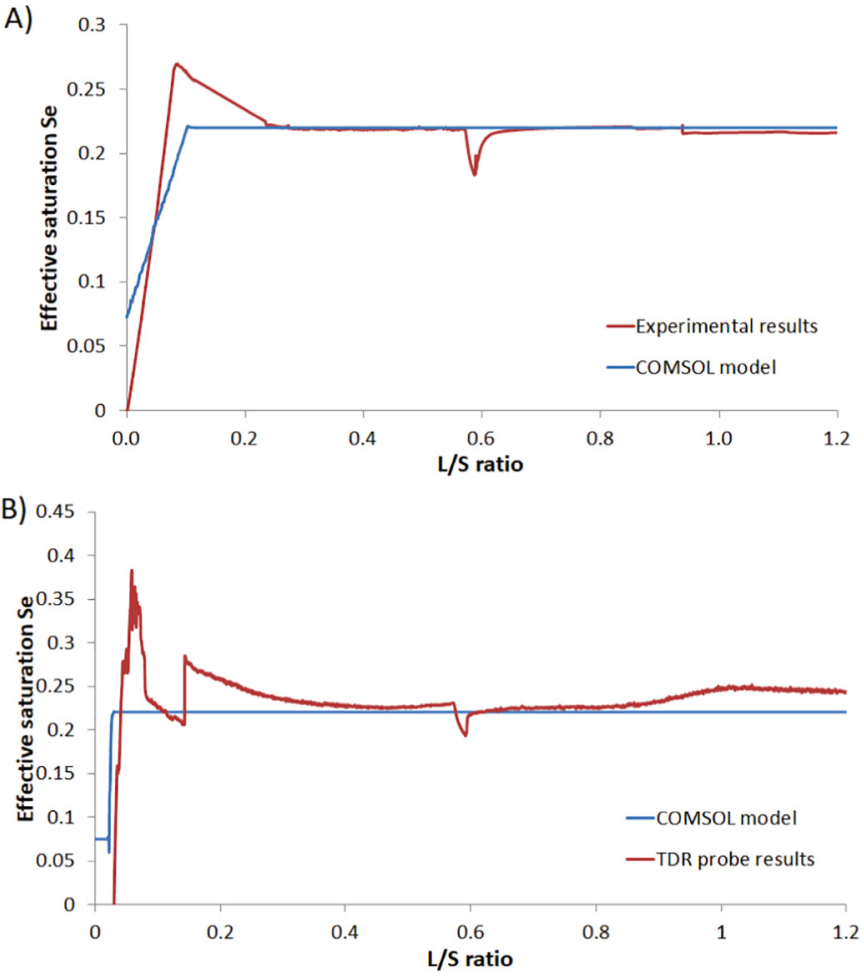

Fig. 6. Comparison of effective saturation evolution during leaching between experimental results and COMSOL model for A) the entire column B) a cross section at $0.3 \mathrm{~m}$ depth within the column.

effect in the upper part of the heap). However, the model fails to reproduce the transient regime and especially the stage when saturation decreases. As previously explained, this mechanical process is due to the settlement of the bed. A more complex model taking into account the hydro-mechanical effects is required so that column permeability and effective compressibility can vary during leach.

\subsubsection{Uranium transport model}

Two mass balance equations were used to describe uranium extraction and transport of the dissolved mineral within the column. As previously mentioned, only uranium mass transport governing equations are considered here, since any geochemical couplings with other mineral species are neglected. We denote by $c_{U}{ }^{s}$ and $c_{U}{ }^{\text {agglo }}$, respectively, the uranium concentration in the acid solution and in the agglomerates. The set of governing differential equations is written as follows:

$\frac{\partial}{\partial t}\left(\theta c_{U}^{s}\right)+\frac{\partial}{\partial z}\left(u c_{U}^{s}\right)=\frac{\partial}{\partial z}\left(D_{U} \frac{\partial}{\partial x} c_{U}^{s}\right)+R_{e f f}$

$(1-\varepsilon) \frac{\partial c_{U}^{a g g l o}}{\partial t}=-R_{e f f}$ 
with $\theta$, the water content, $\mathrm{u}$, the fluid-averaged velocity of the leaching solution inside the column (both determined by the Richards equation in the previous part of the model), $D_{U}$, the axial dispersion coefficient of uranium in water, $\rho_{\text {agglo }}$, the agglomerate density, $\varepsilon$, the column porosity (assumed to be constant in the absence of hydro mechanical couplings) and $R_{\text {eff }}$, the effective reaction rate at the column scale. A constant concentration is imposed at the inlet, $c_{U}^{s}(z=0, t)=0$ and a boundary condition of convective flux type is specified at the outlet. The initial conditions are defined by:

$c_{U}^{s}(z, t=0)=0 c_{\mathrm{U}}^{\mathrm{s}}(\mathrm{z}, \mathrm{t}=0)=0$

$c_{U}^{\text {agglo }}(z, t=0)=c_{U}^{0}=900 \mathrm{ppm}$

The axial dispersion coefficient of uranium flowing through the column was fitted against experimental curves as $D_{U}=3.35 \cdot 10^{-7} \mathrm{~m}^{2}$ / s. The effective reaction rate $R_{\text {eff }}$ is only expressed as a function of the local uranium extraction rate $\chi$, calculated as the ratio between the present mass of recovered uranium and the initial mass of uranium within the agglomerates, i.e.,

$\chi(z, t)=\frac{c_{U}^{0}-c_{U}^{a g g l o}(z, t)}{c_{U}^{0}}$

This effective reaction rate is directly extracted from the apparent reaction rate $R_{R E V}$ measured at the REV-scale, as stated in the assumptions of the model so we have:

$R_{\text {eff }}(\chi)=R_{R E V}(\chi)$

Changes in the reaction rate $R_{R E V}$ as a function of $\chi$ are calculated from REV-scale leaching experiments and plotted in Fig. 7. A polynomial function $f(\chi)$ is fitted on this experimental correlation and used instead in our simulations with COMSOL Multiphysics for the sake of simplicity.

Comparison between experimental and numerical rates of uranium global extraction is reported in Fig. 8. We observe good agreement between the two curves, especially over the long term. The discrepancy during the first one hundred hours of leaching may be attributed to the underestimation of the saturation in the flow model, as a result of the absence of mechanical coupling. Another explanation is the lack of experimental data at the VER-scale for $\mathrm{L} / \mathrm{S}<0.4$ that induces an uncertainty on the effective reaction rate value at the very start of the heap leaching process. This satisfying prediction of uranium leaching extraction is particularly striking since reaction rates were extracted from REV-scale column experiments and apart from the axial dispersion coefficient of uranium, no fitting with the meter -scale column experiments was employed. This comparison justifies the use of smallscale column experiments (i.e. $10 \mathrm{~cm}$ high columns), from which reaction rate were extracted, to investigate uranium-ore agglomerate leaching at the heap scale (i.e. 1 meter scale columns and further 6 to 9 meters high heaps).

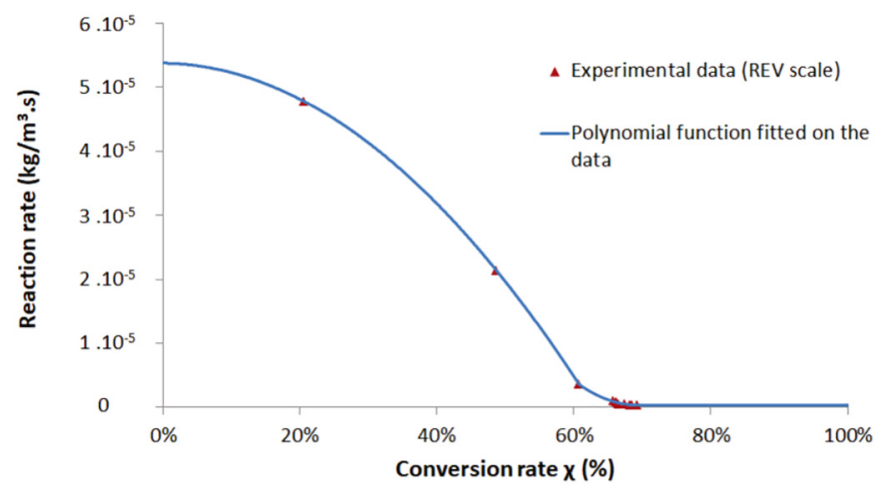

Fig. 7. Relation between the reaction rate and the conversion rate extracted from REV-scale leaching experiments.

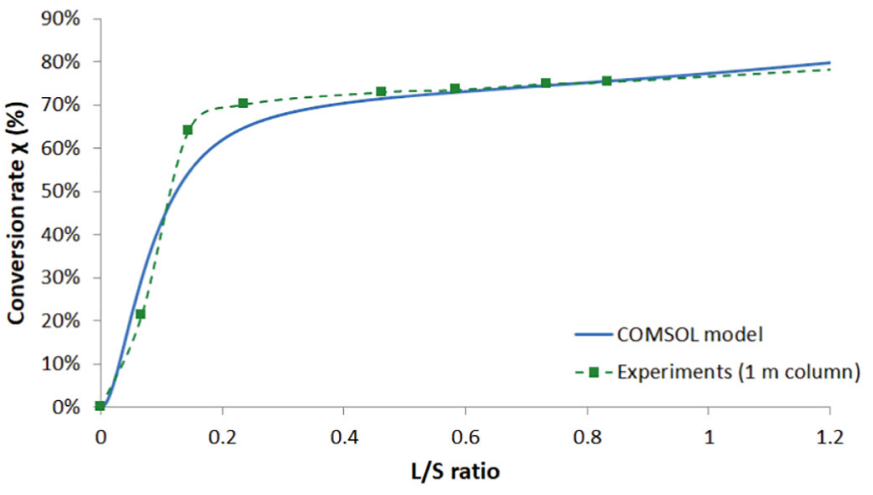

Fig. 8. Changes in the global recovery rate of uranium during leaching and comparison between experimental results ( $0-1 \mathrm{~m}$ column) and COMSOL model.

\section{Conclusions}

The present paper focuses on the column leaching behaviour of uranium-ore agglomerates at different scales, from the representative elementary volume of the heap to the meter-scale columns tests. An original experimental set-up has been used to reproduce and investigate the leaching conditions at various depths within the heap.

The effect of leaching parameters was investigated from REV-scale leaching tests. Based on these results, several physical assumptions were set forth and we derived a numerical model of a 1-meter column of agglomerates, coupling Richards and reaction-advection-diffusion equations to simulate flow within the column and uranium extraction. A good agreement has been found with the meter-scale experiments, representative at the top of the heap.

From the results obtained in this work, our primary findings and recommendations for future work on this topic can be stated as follows:

- Micro-scale (i.e. REV scale) experiments have revealed less or no evidence of mass transfer limitations during uranium-ore agglomerate leaching. This supports the assumption that the overall reaction rate is dominated by kinetics.

- The same series of experiments in $10 \mathrm{~cm}$-columns has highlighted a small impact of the acid concentration in the range of values we investigated. In addition, meter-scale experiments have shown that the sulfuric acid was in excess and not the limiting reactant. Accordingly, we have neglected changes in acid concentration in the numerical model and kept this parameter as constant. However, it should be kept in mind that this assumption is questionable for a heap of 6 to $9 \mathrm{~m}$ high. An additional mass balance equation for the sulfuric acid would be required to extent the model at the heap scale and to describe the acid consumption with depth (and the related impact on the uranium extraction).

- The origin of the plugging problem observed at a macro-scale during heap leaching has been elucidated. First, chemical analyses of the leaching solution have confirmed the small quantity of dissolved calcium and discarded the chemical origin assumption - due to gypsum precipitation - for this plugging. The application of the vertical stress due to the heap weight in meter-scale leaching experiments was found to cause agglomerate degradation, which in turn induces a strong decrease of permeability and porosity, leading to clogging. This clogging mechanism, being purely mechanical, has been confirmed by X-ray tomography imaging. Using stronger agglomerates may be a solution to address this issue and improve leaching efficiency. Preliminary research on the use of polyacrylamide binder with uranium-ore agglomerates and its impact on their mechanical properties have been conducted in Hoummady et al. (in submission). Further columns tests, using such improved agglomerates, would be required to assess their technical applicability at the heap scale. 
- Based on the physical assumptions inferred from REV experiments, we derived a numerical model of acid leaching at the meter-scale. Further improvement of model forecasting capabilities, especially at early times of leaching, will require to integrate mechanical coupling between permeability and compressibility. This 1D model should provide a first basis for application at the heap scale. However, a study of the impact of lateral heterogeneities within a heap and the related channelling effects would be needed. In addition, due to the heap height, some assumptions such as the excess of sulfuric acid or the absence of hydro-mechanical coupling (causing heap plugging) would become invalid. Additional equations will be required for fully describing these couplings and building a predictive model of leaching at the scale of 6 to $9 \mathrm{~m}$ heaps.

\section{Acknowledgments}

The authors gratefully acknowledge the financial support of AREVA Mines, Christophe Morlot and Cedric Demeurie for their help. This work has been carried out thanks to the access to the analytical capabilities of the GeoRessources Laboratory (Université de Lorraine, CNRS, CREGU), with equipment financed by CPER program (National Funds - Lorraine region - FEDER) and Labex Ressources 21 (supported by the French National Research Agency through the national program "Investissements d'avenir") with reference ANR - 10 - LABX 21 LABEX RESSOURCES 21.

\section{References}

Agatzini-Leonardou, S., Zafiratos, I.G., 2004. Beneficiation of a Greek serpentinic nickeliferous ore Part II. Sulphuric acid heap and agitation leaching. Hydrometallurgy 74, 267-275. http://dx.doi.org/10.1016/j.hydromet.2004.05.006.

Bartlett, R.W., 1997. Metal extraction from ores by heap leaching. Metall. Mater. Trans. B Process Metall. Mater. Process. Sci. 28, 529-545. http://dx.doi.org/10.1007/s11663997-0026-2.

Bennett, C.R., McBride, D., Cross, M., Gebhardt, J.E., 2012. A comprehensive model for copper sulphide heap leaching. Hydrometallurgy 127, 150-161. http://dx.doi.org/ 10.1016/j.hydromet.2012.08.004.

Bouffard, S.C., 2005. Review of agglomeration practice and fundamentals in heap leaching. Miner. Process. Extr. Metall. Rev. 26, 233-294. http://dx.doi.org/10.1080/ 08827500590944009.

Bouffard, S.C., Dixon, D.G., 2001. Investigative study into the hydrodynamics of heap leaching processes. Metall. Mater. Trans. B Process Metall. Mater. Process. Sci. 32, 763-776. http://dx.doi.org/10.1007/s11663-001-0063-1.

Bouffard, S.C., West-Sells, P.G., 2009. Hydrodynamic behavior of heap leach piles: influence of testing scale and material properties. Hydrometallurgy 98, 136-142. http://dx.doi.org/10.1016/j.hydromet.2009.04.012.

Dhawan, N., Safarzadeh, M.S., Miller, J.D., Moats, M.S., Rajamani, R.K., 2013. Crushed ore agglomeration and its control for heap leach operations. Miner. Eng. 41, 53-70. http://dx.doi.org/10.1016/j.mineng.2012.08.013.

Dixon, D.G., 2000. Analysis of heat conservation during copper sulphide heap leaching Hydrometallurgy 58, 27-41. http://dx.doi.org/10.1016/S0304-386X(00)00119-5.

Dixon, D.G., 2003. Heap leach modeling - the current state of the art. In: Hydrometallurgy. The Minerals, Metals \& Materials Society, Warrendale, pp.
289-314.

Dixon, D.G., Hendrix, J.L., 1993. A mathematical model for heap leaching of one or more solid reactants from porous ore pellets. Metall. Trans. B 24, 1087-1102. http://dx. doi.org/10.1007/BF02661000.

D.G., Dixon, Petersen, J., 2003. Comprehensive modeling study of chalcocite column and heap bioleaching. In: Presented at the Copper 2003 - Cobre 2003, International Conference, 5, Montreal, pp. 493-516.

Genuchten, Van, 1980. A closed-form equation for predicting the hydraulic conductivity of unsaturated soils 1. Soil Sci. Soc. Am. J. 44, 892-898. http://dx.doi.org/10.2136/ sssaj1980.03615995004400050002x.

Ghorbani, Y., Becker, M., Mainza, A., Franzidis, J.-P., Petersen, J., 2011. Large particle effects in chemical/biochemical heap leach processes - a review. Miner. Eng., Spec. Issue: Bio Hydrometal. 24, 1172-1184. http://dx.doi.org/10.1016/j.mineng.2011. 04.002 .

Ghorbani, Y., Franzidis, J.-P., Petersen, J., 2016. Heap leaching technology-current state, innovations, and future directions: a review. Miner. Process. Extr. Metall. Rev. 37, 73-119. http://dx.doi.org/10.1080/08827508.2015.1115990.

Golfier, F., Quintard, M., Cherblanc, F., Zinn, B.A., Wood, B.D., 2007. Comparison of theory and experiment for solute transport in highly heterogeneous porous medium. Adv. Water Resour. 30, 2235-2261. http://dx.doi.org/10.1016/j.advwatres.2007.05. 004.

Hoummady, E., Golfier, F., Cathelineau, M., Truche, L., Durupt, N., Blanvillain, J.-J., Neto, J., Lefevre, E., 2017. A multi-analytical approach to the study of uranium-ore agglomerate structure and porosity during heap leaching. Hydrometallurgy 171 33-43. http://dx.doi.org/10.1016/j.hydromet.2017.04.011.

Kodali, P., Depci, T., Dhawan, N., Wang, X., Lin, C.L., Miller, J.D., 2011. Evaluation of stucco binder for agglomeration in the heap leaching of copper ore. Miner. Eng. 24, 886-893. http://dx.doi.org/10.1016/j.mineng.2011.03.024.

Mellado, M.E., Cisternas, L.A., Gálvez, E.D., 2009. An analytical model approach to heap leaching. Hydrometallurgy 95, 33-38. http://dx.doi.org/10.1016/j.hydromet.2008. 04.009.

Mualem, Y., 1976. A new model for predicting the hydraulic conductivity of unsaturated porous media. Water Resour. Res. 12, 513-522. http://dx.doi.org/10.1029/ WR012i003p00513.

Nosrati, A., Addai-Mensah, J., Robinson, D.J., 2012a. Drum agglomeration behavior of nickel laterite ore: effect of process variables. Hydrometallurgy 125-126, 90-99. http://dx.doi.org/10.1016/j.hydromet.2012.05.016.

Nosrati, A., Skinner, W., Robinson, D.J., Addai-Mensah, J., 2012b. Microstructure analysis of Ni laterite agglomerates for enhanced heap leaching. Powder Technol. 232, 106-112. http://dx.doi.org/10.1016/j.powtec.2012.08.016.

Ogbonna, Petersen, Laurie, 2006. An agglomerate scale model for the heap bioleaching of chalcocite. J. South. Afr. Inst. Min. Metall. 106, 433-442.

Petersen, J., 2016. Heap leaching as a key technology for recovery of values from lowgrade ores - a brief overview. Hydrometallurgy 206-212. SI: IC-LGO 2015 165, Part 1. https://doi.org/10.1016/j.hydromet.2015.09.001.

Pietsch, W., 2002. Agglomeration Processes: Phenomena, Technologies, Equipment. Wiley-VCH Verlag GmbH.

Robertson, S., 2017. Development of an integrated heap leach solution flow and mineral leaching model. Hydrometallurgy 169, 79-88. http://dx.doi.org/10.1016/j. hydromet.2016.12.010

Sheikhzadeh, G.A., Mehrabian, M.A., 2007. Simulation of heap leaching process in a bed of porous and spherical ore particles. Int. J. Numer. Methods Heat Fluid Flow 17 638-653. http://dx.doi.org/10.1108/09615530710761252.

Valencia, J.A., Méndez, D.A., Cueto, J.Y., Cisternas, L.A., 2008. Saltpeter extraction and modelling of caliche mineral heap leaching. Hydrometallurgy 90, 103-114. http:// dx.doi.org/10.1016/j.hydromet.2007.10.001.

Yijun, Z., Jianhua, L., Tieqiu, L., Pingru, Z., 2004. Application of agglomerated acid heap leaching of clay-bearing uranium ore in China. In: Presented at the Recent Developments in Uranium Resources and Production with Emphasis on In Situ Leach Mining, pp. 243-249. 